\title{
Management of Segment Failure Post Lumbar Fixation by One Level Extension of Fixation
}

\author{
AHMED KOHEIL, M.D. and MAHMOUD RAMADAN, M.D. \\ The Department of Neurosurgery, Faculty of Medicine, Beni Suef University
}

\begin{abstract}
Background: Lumbosacral fixation is a common surgical procedure for various indications including spondylolithesis with neurogenic claudication pain secondary to degenerative spinal canal stenosis. Segment failure following lumbosacral fixation is a serious complication resulting from spondylolithesis above or below fixed vertebrae. Segment failure is an important cause of recurrence of symptoms and/or appearance of new symptoms. This complication must be properly diagnosed and managed to improve short and long term surgery outcome.
\end{abstract}

Aim of Study: This study aimed to assess the management of segment failure post lumbar fixation by one level extension of fixation.

Patients and Methods: This study included 15 patients presenting with segment failure post lumbar fixation. Inclusion criteria was improvement of pain and/or neurologic claudication after initial lumbar fixation. The occurrence of segment failure was documented by lumbosacral magnetic resonance imaging MRI. All patients were managed by one level extension of fixation.

Results: Patients were five (33.3\%) females and ten $(66.6 \%)$ males with an age that ranged from 33 to 67 years, mean age was $48 \pm 5.8$ years. Body mass index BMI ranged from 23.6 to 35.7 with a mean of $31.4 \pm 3.7 \mathrm{~kg} / \mathrm{m}^{2}$. All patients were complaining from low back pain LBP, had radicular pain and presented with neurologic claudication. The duration between the initial lumbosacral fixation surgery and the operation for extension of fixation ranged from 1.7 to 3.1 years with a mean of $2.5 \pm 1.7$ years.

Conclusion: Segment failure is an importantcause of recurrence of symptoms after primary relief following lumbar fusion surgery. One level extension of fixation is a good option for management of segment failure post lumbar fixation.

Key Words: Lumbar fixation - Segment failure - Spinal fusion.

\section{Introduction}

THERE is controversy regarding the subsequent degeneration of adjacent segments following posterior lumbar decompression and fusion $[\mathbf{1 , 2 , 3}$.

Correspondence to: Dr. Ahmed Koheil,

E-Mail: akoheil@med.bsu.edu.eg
Although efforts to preserve segmental motion during spinal surgery are now increasing, spinal fusion remains a standard method of surgical treatment for deformity, trauma and degenerative disorders $[4,5,6]$. Fusion clinical success rates have increased due to improvements in instrumentation and bone graft material. In contrast, numerous complications and problems of fusion surgery have been reported with adjacent segment disease being one of the most important $[\mathbf{7 , 8 , 9 ]}$.

Suggested explanations for segment failure include abnormal loading and increased mobility in adjacent segments but it is still unclear whether this results from fusion sequel or it is result of natural degeneration $[10,11,12]$

There have been also controversy about the exact incidence of adjacent segment failure and its risk factors. It is evident that the number of cases of adjacent segment failure will increase as the number of performed surgeries for fixation increase. However only few reports were done on the benefits of revision surgeries [13]

\section{Patients and Methods}

The current study included 15 patients who had spinal fusion surgery by one level extension to the previous fixation due to adjacent segment failure during the period from January 2019 to December 2020 in Beni Suef University Hospital. Patients were followed-up for the next 6 month following surgery to detect postoperative complications. The study conformed to the provisions of the Declaration of Helsinki. All participants gave a written informed consent.

Inclusion criteria for the patients included:

- Improvement of the initial complaint either from the back or leg symptoms. 
- Non traumatic causes for spinal fusion.

- No neurological problem appeared immediately postoperative.

- No presence of tumors.

- No presence of vascular malformations.

All patients were subjected to full neurological exam and full history taking before surgery.

Patients were recruited from the outpatient clinic, they came for follow-up after previous lumbar fixation. Study group patients had new symptoms i.e. back or leg pain after an initial period of relief. Diagnosis was confirmed by magnetic resonance imaging MRI. Medical treatment and physiotherapy were started. Patients who did not respond to conservative measures were subjected to surgery in which an extension for fixation was done by one level above.

Fifteen patients were included in the current study, none of these patients had spinal fractures, spinal neoplasms nor vascular malformations. Among the 15 patients $33 \%$ were females and $67 \%$ were males and the mean age was 48 years and the oldest was 33 years old and the oldest was 67 . The mean body mass index BMI for the participants was $31.4 \mathrm{Kg} / \mathrm{m}^{2}$. Eleven patients $(73.3 \%)$ were complaining from radicular pain and 93.3\% (14 patients) were complaining of claudication pain and all of the 15 patients were complaining of back pain. The average interval between the first and second operation was 2.5 years. Statistical Methods: Data were statistically described in terms of mean \pm standard deviation $( \pm S D)$, median and range, or frequencies (number of cases) and percentages when appropriate. Two sided $p$-values less than 0.05 was considered statistically significant. All statistical calculations were done using computer program IBM SPSS (Statistical Package for the Social Science; IBM Corp, Armonk, NY, USA) release 22 for Microsoft Windows.

\section{Results}

Fifteen patients were included in this study who came with recurrence of symptoms and images confirming segment failure following lumbar fusion. Among the 15 patients $33.3 \%$ were females and $66.6 \%$ were males and the mean age was 48 years and the youngest was 33 years old and the oldest was 67. The mean body mass index for the participants was $31.4 \mathrm{~kg} / \mathrm{m}^{2}$, the lowest body mass index was 25 and the highest was 40 . Eleven of the patients $(73.3 \%)$ were complaining of radicular pain and fourteen patients (93.3\%) were complaining of claudication pain and all of the 15 patients were complaining of back pain. The average interval between the first and second operation was 2.5 years. The adjacent segment failure was cranial to the previous fusion in all cases. Type of work and failed level. Postoperative there was immediate improvement in all patients.

Table (1): Shows demographic data and graph-1 shows preoperative symptoms.

\begin{tabular}{lccl}
\hline & Minimum & Maximum & Mean \\
\hline Age (years) & 33 & 67 & 48 \\
BMI (Kg/m ${ }^{2}$ ) & 25 & 40 & 31.4 \\
Interval between & 1 & 4 & 2.5 years \\
$\quad$ spinal surgeries (years) & & & \\
\hline
\end{tabular}

Table (1): Demographic data:

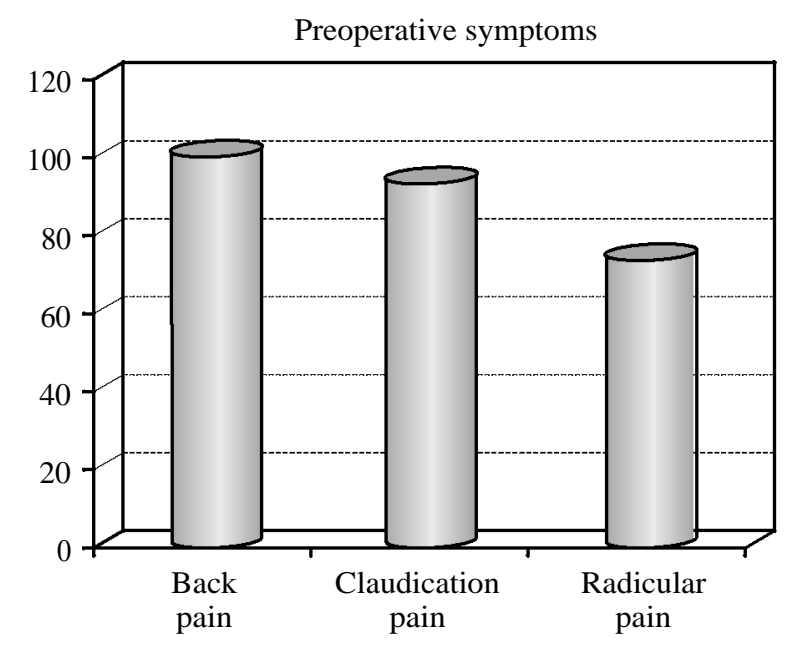

Fig. (1): Pre-operative symptoms.

\section{Discussion}

The real reason behind adjacent segment failure is not precisely known. Studies done showed a lead towards the biomechanical stress which may increase at the adjacent segment following fixation due to physiological loading at that segment which may lead to speeding the degenerative process in the disc and joints. However the cause may be as simple as ignoring a weak segment from the start during fixation. Theoretically if this segment was put into consideration, no segment failure would have occurred $[4,8,13]$.

Several studies have tried to document causes that are directly related to adjacent segment failure. Liuke et al., [3] stated the fact that a body mass index above $25 \mathrm{~kg} / \mathrm{m}^{2}$ is directly related to adjacent segment failure and speeds the process of disc degeneration. Bagheri et al., [2] also reached the 
same conclusion that body mass index is directly related to the development of adjacent segment disease the higher the body mass index the higher possibility of segment failure.

The previous results are consistent with our study in which all patients had body mass index greater than $25 \mathrm{~kg} / \mathrm{m}^{2}$.

Several studies directly related adjacent segment failure and age suggesting that age is a predisposing factor for the adjacent segment disease. However in our study there was no relation to patients' age. The mean age was 48 years and the youngest was 33 years old and the oldest was 67 which is consistent with the study by Radcliff et al., [7] .

The relation between length fusions and adjacent segment disease development is still debatable in studies concerned with this subject. Several authors prefer the relation and confirms the fact that longer length fusions are more likely to develop adjacent segment failure [10]

In the current study, there were no direct relation between segment length and occurrence of segment failure.

The mean time interval before the second operation in our study was 2.5 years and range from minimum of 1 year and maximum of 4 years. This duration was much longer than the interval reported by Okuda et al., [1] in which the mean average period for the second operation was 4.7 years.

The difference in duration may result from the fact that we searched for segment failure patients very early when they came for follow-up after initial fixation [7,9].

In this study, there was an improvement concerning the newly developed symptoms after performing a one level extension of fusion. Further assessment and longer follow-up period are recommended before judgment, also this study was not designed to discuss the causes of adjacent segment failure which should be further investigated thoroughly.

\section{Conclusion:}

Segment failure is a well-known complication after lumbar fixation surgery. Managing this complication by one level extension was successful in our study group.
Disclosure: The author declares he had no disclosures.

\section{References}

1- OKUDA S., IWASAKI M., MIYAUCHI A., AONO H., MORITA M. and YAMAMOTO T.: Risk factors for adjacent segment degeneration after PLIF. Spine (Phila Pa 1976), 29: 1535-40, 2004.

2- BAGHERI S.R., ALIMOHAMMADI E., ZAMANI FROUSHANI A., et al.: Adjacent segment disease after posterior lumbar instrumentation surgery for degenerative disease: Incidence and risk factors. J. Orthop. Surg. (Hong Kong), 27: 2309499019842378, 2019.

3- LIUKE M., SOLOVIEVA S., LAMMINEN A., et al.: Disc degeneration of the lumbar spine in relation to overweight. Int. J. Obes. (Lond), 29: 903-8, 2005.

4- LEE J.C., LEE S.H., PETERS C. and RIEW K.D.: Adjacent segment pathology requiring reoperation after anterior cervical arthrodesis: The influence of smoking, sex, and number of operated levels. Spine (Phila Pa 1976), 40: E571-E577, 2015.

5- MARCHI L., OLIVEIRA L., COUTINHO E. and PIMENTA L.: Results and complications after 2-level axial lumbar interbody fusion with a minimum 2-year followup. J. Neurosurg Spine, 17: 187-192, 2012.

6- GILLET P.: The fate of the adjacent motion segments after lumbar fusion. J. Spinal Disord Tech., 16: 338-345, 2003.

7- RADCLIFF K.E., KEPLER C.K., JAKOI A., SIDHU G.S., RIHN J., VACCARO A.R., et al.: Adjacent segment disease in the lumbar spine following different treatment interventions. Spine J., 13: 1339-1349, 2013.

8- PARK P., GARTON H.J., GALA V.C., HOFF J.T. and McGILLICUDDY J.E.: Adjacent segment disease after lumbar or lumbosacral fusion: Review of the literature. Spine (Phila Pa 1976), 29: 1938-44, 2004.

9- KUMAR M.N., BAKLANOV A. and CHOPIN D.: Correlation between sagittal plane changes and adjacent segment degeneration following lumbar spine fusion. Eur. Spine J., 10: 314-9, 2001.

10- ETEBAR S. and CAHILL D.W.: Risk factors for adjacentsegment failure following lumbar fixation with rigid instrumentation for degenerative instability. J. Neurosurg, 90: 163-9, 1999.

11- BERNHARDT M. and BRIDWELL K.H.: Segmental analysis of the sagittal plane alignment of the normal thoracic and lumbar spines and thoracolumbar junction. Spine (Phila Pa 1976), 14: 717-21, 1989.

12- NAKASHIMA H., KAWAKAMI N., TSUJI T., et al.: Adjacent segment disease after posterior lumbar interbody fusion: Based on cases with a minimum of 10 years of follow-up. Spine (Phila Pa 1976), 40: E831-41, 2015.

13- HAMBLY M.F., WILTSE L.L., RAGHAVAN N., et al.: The transition zone above a lumbosacral fusion. Spine (Phila Pa 1976), 23: 1785-92, 1998. 


\section{علاج ضيق القناة العصبية فوق مستوى التثبيت

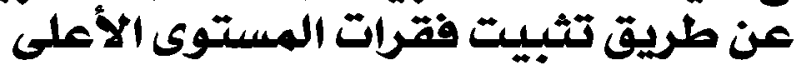 مع توسيع القناة العصبية فئية المبية}

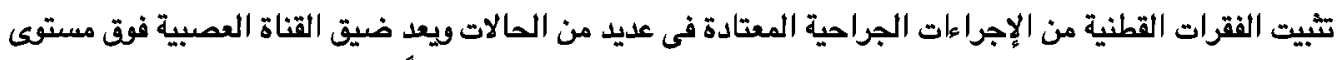

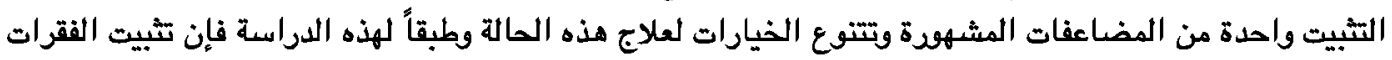

هذا المستوى الأعلى مع توسيع القناة العصبية من الخيارات الناجحة لعلاج هذه العنات الحالة. 